Joseph Bernard B. Lo, MD

Emmanuel Tadeus S. Cruz, MD,

Department of Otorhinolaryngology

Head and Neck Surgery

Quezon City General Hospital
Correspondence: Dr. Emmanuel Tadeus S. Cruz

Department of Otorhinolaryngology

Head and Neck Surgery

Quezon City General Hospital

Seminary Road, Barangay Bahay Toro, Quezon City 1106

Philippines

Phone: (632) 9088728655

Email:emancrz@yahoo.com

The authors declared that this represents original materia that is not being considered for publication or has not been published or accepted for publication elsewhere in full or in part, in print or electronic media; that the requirements for authorship have been met by all the authors, and that each author believes that the manuscript represents honest work.

Disclosures: The authors signed a disclosure that there are no financial or other (including personal) relationships, intellectual passion, political or religious beliefs, and institutional affiliations that might lead to a conflict of interest.

Presented at the Philippine Society of Otolaryngology Head and Neck Surgery Analytical Research Contest. December 6, 2019. Palawan Ballroom, Edsa Shangri-La Hotel, Mandaluyong City.

\section{$\Theta(\Theta \Theta$}

Efficacy of Carragelose ${ }^{\circledast}$ Nasal Spray Impregnated Versus Mupirocin Ointment Impregnated Nasal Packs on Mucosal Healing after Endoscopic Sinus Surgery: A Double-Blind, Non-Randomized, Right-Left Side Comparison

\begin{abstract}
Objective: To determine the efficacy of carragelose ${ }^{\circ}$ nasal spray versus mupirocin ointment impregnated nasal packs on postoperative mucosal healing among chronic rhinosinusitis with
\end{abstract} nasal polyposis (CRSwNP) patients after endoscopic sinus surgery (ESS).

Methods:

Design: $\quad$ Double-Blind, Non-Randomized, Right-Left Side Comparison

Setting: $\quad$ Tertiary Government Training Hospital

Participants: Fifteen (15) patients diagnosed with chronic rhinosinusitis with nasal polyposis (CRSwNP) who had ESS were included in the study. Nasal packs (Netcell ${ }^{\circ}$ ) impregnated with carragelose ${ }^{\circ}$ nasal spray or mupirocin ointment were respectively applied in right and left nostrils. Postoperative mucosal healing was graded by a blinded consultant using the LundKennedy Endoscopic Scoring System and Perioperative Sinus Endoscopy (POSE) scoring system.

Results: Six patients (12 nasal sides) completed the study. Comparing nasal packs impregnated with carragelose ${ }^{\circ}$ nasal spray mupirocin ointment, the carragelose group had lower LundKennedy median scores than the mupirocin group on the $7^{\text {th }}$ post-operative day; and this was statistically significant ( $p=.027$ ). There were no significant differences in Lund-Kennedy postoperative scores on days $4(p=.217), 14(p=.171)$ and $28(p=.151)$.

Conclusion: Carragelose nasal spray impregnated nasal packs may be comparable with, and may be an alternative to mupirocin ointment impregnated nasal packs in terms of postoperative mucosal healing among ESS patients with CRSwNP.

Keywords: carragelose; mupirocin; nasal pack, endoscopic sinus surgery, nasal polyp 


\section{ORIGINAL ARTICLES}

Application of nasal packs is common practice after endoscopic sinus surgery (ESS) to control post-operative bleeding, facilitate remucosalization of the sinonasal cavity and convey medications to the operative site. ${ }^{1-3}$ In our institution, mupirocin topical ointment USP, $2 \%$ has been commonly used to impregnate nasal packs with good experience and no untoward effects. ${ }^{2-4}$ However, mupirocin is not the only available agent. Various medications can be applied to nasal packs and there appears to be no agreement on which drug is better. ${ }^{5-6}$

Carragelose ${ }^{\circ}$ is a polysaccaharide carbohydrate obtained from red seaweeds, Chondrus crispuse species. ${ }^{6}$ This species is common in the Atlantic Ocean and also abundant in the Philippines. ${ }^{6}$ It is used for meat processing, personal care and pet food products and in recent years as medicine. ${ }^{6}$ Carragelose ${ }^{\circ}$ is claimed to have multiple properties including anticoagulant, antithrombotic, anti-tumor and immunomodulatory. ${ }^{6.8}$ Carragelose ${ }^{\circ}$ nasal spray (Betadine"m Marinomed Biotech AG, Mundipharma Laboratories $\mathrm{GmbH}$ ) is used to shorten the duration of common colds primarily by trapping and clearing viruses in mucus, hindering their binding or entry into the cell. ${ }^{6}$ To the best of our knowledge, a search of HERDIN, MEDLINE (PubMed), Cochrane and Google Scholar revealed no published study on the use of carragelose on nasal packing after ESS.

As part of our quest for alternative medications to apply on nasal packs, this study was conducted to determine the efficacy of carragelose nasal spray - impregnated versus mupirocin ointment impregnated nasal packs on postoperative mucosal healing after ESS for chronic rhinosinusitis with nasal polyposis (CRSwNP).

\section{METHODS}

This prospective, double-blind, non-randomized, right-left side comparison was conducted with approval of the Bioethics Committee of the Quezon City General Hospital. Patients diagnosed with CRSwNP who underwent ESS from October 2018 to August 2019 were considered for inclusion in the study. The following were excluded: patients with past history of nasal surgery because of a tumor other than nasal polyp, recurrent nasal polyposis, presence of co-morbidities such as diabetes mellitus, uncontrolled hypertension, immunocompromised condition, those on anticoagulant therapy and with bleeding disorders.

The sample size was computed with mean difference and standard deviations based on the data presented in the study of Promentilla et al. ${ }^{9}$ A significance level of 0.05 and power of $80 \%$ were used in computation. A drop-out rate of $20 \%$ was used to calculate the adjusted sample size using the following formula.

$$
\begin{aligned}
& n \geq \frac{2 \sigma^{2}\left(Z_{\alpha / 2}+Z_{\beta}\right)^{2}}{d^{2}} \\
& n_{\text {adiusted }}=1.2(n)
\end{aligned}
$$

Where:

$\boldsymbol{n}$ is the minimum sample size for each group to detect whether the stated difference exists between the two means

$Z_{\alpha / 2}$ is the critical value of the normal distribution at $\alpha / 2$ (e.g. for a confidence level of $95 \%, a$ is 0.05 and the critical value is 1.96 )

$Z_{\beta}$ is the critical value of the normal distribution at $\beta$ (e.g. for a power of $80 \%, \beta$ is 0.2 and the critical value is 0.84 ),

$\sigma^{2}$ is the population variance; and

$\boldsymbol{d}$ is the difference you would like to detect.

The sample size used in this study had a $95 \%$ confidence level and a power of $80 \%$, with detectable difference of 1.0 and standard deviation of 1.0. The ideal sample size was 16 subjects with a total of 32 nasal sides.

Histories with emphasis on rhinologic problems were obtained, and otorhinolaryngoscopic examinations, nasal endoscopies and subsequent grading of nasal polyposis using the Lund-McKay classification were performed. Preoperatively, patients were prescribed cefuroxime $500 \mathrm{mg} / \mathrm{tab}$ twice a day for one week and prednisone $20 \mathrm{mg} / \mathrm{tab}$ every eight hours for one week. The ESS was performed on each patient by an assigned ear, nose and throat (ENT) senior surgical resident. In patients with an antrochoanal polyp, ESS with CaldwellLuc procedure was performed on the affected side with ESS on the contralateral side for chronic rhinosinusitis.

After surgery, an ENT surgical resident who was not part of the study inserted a $4 \mathrm{~cm} \times 2 \mathrm{~cm}$ nasal pack (Netcelli) impregnated with carragelose nasal spray or mupirocin ointment in the right and left nostrils respectively, under supervision by the principal investigator. The patients (still under anesthesia) were blinded to this treatment. The identity of medications was not concealed from the surgeons because the containers were recognizable and the medications were applied differently: carragelose ${ }^{\circ}$ was sprayed on the right nasal packs after pack insertion, while mupirocin was coated on the left nasal packs before pack insertion.

Intravenous cefuroxime $750 \mathrm{mg}$ every 8 hours and ketorolac $30 \mathrm{mg}$ as needed were given post-operatively for the first 24 hours after surgery then shifted to oral cefuroxime $500 \mathrm{mg} / \mathrm{tab}$ twice daily and celecoxib $200 \mathrm{mg} / \mathrm{cap}$ twice daily as needed for the next 7 days. 
Nasal packs in both nostrils were removed on the $4^{\text {th }}$ post-operative day then nasal saline irrigation with suctioning to clean the nasal cavity was followed by video-endoscopy using a Karl-Storz Tricam SL II and Xenon Nova 300, all performed by the assigned surgeon. Patients visited the out-patient department on the 7 th, $14^{\text {th }}$ and $28^{\text {th }}$ postoperative days for follow-up and documentation of post-operative site healing using the same video nasal endoscopy set-up, also performed by the same surgeon.

The Lund-Kennedy Endoscopic Scoring System ${ }^{10}$ and Perioperative Sinus Endoscopy (POSE) scoring system ${ }^{11}$ were used to grade postoperative mucosal healing. The former scored each of 5 parameters (presence of nasal polyp, discharge severity of mucosal edema, scarring, crusting) on a scale of 0 to $2 .^{10}$ The latter additionally assessed the middle turbinate (normal, synechia, lateralized), middle meatus (normal, narrowed, complete obstruction / stenosis) maxillary sinus content (normal, edema or thin discharge, purulent or allergic mucin), maxillary and ethmoid cavity, as well as frontal and sphenoid sinuses (if operated on), also scoring each on a scale of 0 to $2 .{ }^{11} \mathrm{~A}$ Lund-Kennedy score of 10 or POSE score of 16 were used to indicate post-operative complications which may compromise healing; with lower scores signifying better healing.

A blinded ENT consultant graded the recorded video endoscopic findings of each patient (for the $4^{\text {th }}, 7^{\text {th }}, 14^{\text {th }}$, and $28^{\text {th }}$ day) in one sitting, using the Lund-Kennedy Endoscopic Scoring System ${ }^{10}$ and Perioperative Sinus Evaluation Scoring System. ${ }^{11}$

The consultant-recorded score, and demographic and clinical characteristics of patients were collated, tabulated and recorded in Microsoft ${ }^{\circ}$ Excel version 2016 (Microsoft Corp., Redmond WA USA). Numerical data were summarized using mean, median and standard deviation with minimum and maximum values. Categorical data were presented as frequencies and percentages. Group means of numerical variables were computed, then compared using Mann-Whitney $\mathrm{U}$ test and Friedman test at $5 \%$ level of significance. Additional computations were performed using PH Stat version 4.51 (Prentice-Hall, Inc., Pearson Education, London, UK).

\section{RESULTS}

Initially, there were 17 patients who satisfied inclusion and exclusion criteria, but two patients did not complete the study because one was diagnosed postoperatively with inverting papilloma and another had profuse bleeding due to hypertension. Hence, a total of 15 patients (30 nasal cavities) were initially included in this study; 8 males (53.3\%) and 7 females (46.7\%) with mean age of $41.8 \pm 15.8$ years (range 14 to 74 years old).
Twelve (12) out of 15 patients were diagnosed with chronic rhinosinusitis with bilateral nasal polyposis and underwent bilateral endoscopic sinus surgery under general anesthesia. Two (2) out of these 12 patients had deviated nasal septum and underwent septoplasty as well. Three (3) out of 15 patients were diagnosed with chronic rhinosinusitis with antrochoanal polyp and underwent bilateral endoscopic sinus surgery and a Caldwell-Luc procedure under general anesthesia. One patient was lost to follow-up on day 7 and 4 patients each were lost to follow up on days 14 and 28 . Hence, only 6 patients or 12 nasal cavities completed the study.

Lund-Kennedy median scores were only significantly different on day seven for the carragelose $e^{\circ}$ side $(\mathrm{Mdn}=2.50, \mathrm{IQR}=2.50)$ compared to the mupirocin side ( $M d n=4.00, I Q R=3.75$ ) [Mann-Whitney $u=50.0$; $\mathrm{p}=.027]$. They were not significant on day four (carragelose $\mathrm{Mdn}=$ 3.00, IQR = 2.00; mupirocin Mdn = 5.00, SD = 3.75) [Mann-Whitney $u=$ 82.0; $\mathrm{p}=.217$ ]; day 14 (carragelose $\mathrm{Mdn}=2.00, \mathrm{IQR}=1.25$; mupirocin Mdn $=4.00, I Q R=4.00$ ) [Mann-Whitney $u=39.0 ; p=.171]$; and day 28 (carragelose $\mathrm{Mdn}=2.00, \mathrm{IQR}=1.25$; mupirocin $\mathrm{Mdn}=2.00, \mathrm{IQR}=2.00$ ) [Mann-Whitney $u=38.5 ; p=.151]$. (Table 1)

Using the Friedman test statistic to evaluate differences in medians among the Lund-Kennedy scores on the carragelose ${ }^{\circ}$ side showed significant differences $\left(X^{2}(3)=15.1, p=.002\right)$; evaluation of the mupirocin side also showed significant differences in medians $\left(X^{2}(3)=\right.$ $16.2, p=.001)$. (Table 1)

Table 1. Comparison of Lund-Kennedy scores for Carragelose ${ }^{\ominus}$ and Mupirocin Sides

\begin{tabular}{|c|c|c|c|c|c|c|c|}
\hline \multirow{2}{*}{$\begin{array}{l}\text { Daysfrom } \\
\text { operation }\end{array}$} & \multirow{2}{*}{$\mathbf{n}$} & \multicolumn{2}{|c|}{ Carragelose ${ }^{\ominus}$ Side } & \multicolumn{2}{|c|}{ Mupirocin Side } & \multicolumn{2}{|c|}{ Mann-Whitney U-test } \\
\hline & & Median & IQR & Median & IQR & U-score & P-value \\
\hline 4 & 15 & 3.00 & 2.00 & 5.00 & 3.75 & 82.0 & $.217^{\text {ns }}$ \\
\hline 7 & 14 & 2.50 & 2.50 & 4.00 & 4.25 & 50.0 & $.027^{\text {sig }}$ \\
\hline 14 & 11 & 2.00 & 1.25 & 4.00 & 4.00 & 39.0 & $.171^{\text {ns }}$ \\
\hline 28 & 11 & 2.00 & 1.25 & 2.00 & 2.00 & 38.5 & $.151^{\mathrm{ns}}$ \\
\hline \multirow{4}{*}{\multicolumn{2}{|c|}{ Friedman Test }} & \multicolumn{2}{|c|}{$n=11$} & \multicolumn{2}{|c|}{$n=11$} & & \\
\hline & & \multicolumn{2}{|c|}{$d f=3$} & \multicolumn{2}{|c|}{$d f=3$} & & \\
\hline & & \multicolumn{2}{|c|}{ Chi-square $=15.1$} & \multicolumn{2}{|c|}{ Chi-square= 16.2} & & \\
\hline & & \multicolumn{2}{|c|}{ P-value $=.002^{\text {sig }}$} & \multicolumn{2}{|c|}{ P-value $=.001^{\text {sig }}$} & & \\
\hline
\end{tabular}

Peri Operative Sinus Evaluation (POSE) median scores were not significant on day four (carragelose $\mathrm{C}^{\circ} \mathrm{Mdn}=5.00, \mathrm{IQR}=0.25$; mupirocin $M d n=5.00, I Q R=1.50$ ) [Mann-Whitney $u=82.0 ; p=.217$ ]; day seven (carragelose $\mathrm{Mdn}=4.00, \mathrm{IQR}=2.25$; mupirocin $\mathrm{Mdn}=5.00, \mathrm{IQR}=2.25$ ) [Mann-Whitney $u=70.5 ; p=.210$ ]; day 14 (carragelose ${ }^{\circ} \mathrm{Mdn}=3.00$, IQR $=1.50$; mupirocin $\mathrm{Mdn}=4.00, \mathrm{IQR}=2.00$ ) [Mann-Whitney $u=40.0 ; \mathrm{p}=$ 481]; and day 28 (carragelose $\mathrm{Mdn}=2.00, \mathrm{IQR}=1.25$; mupirocin $\mathrm{Mdn}=$ 3.00, IQR = 3.25) [Mann-Whitney $u=33.0 ; \mathrm{p}=.218]$. 


\section{ORIGINAL ARTICLES}

Using the Friedman test statistic to evaluate differences in medians among the POSE scores on the carragelose side showed significant differences $\left(X^{2}(3)=22.3, p=<.001\right)$; evaluation of the mupirocin side also showed significant differences $\left(X^{2}(3)=15.1, p=.002\right)$. (Table 2)

Table 2. Comparison of Peri Operative Sinus Evaluation (POSE) scores for Carragelose ${ }^{\circledast}$ and Mupirocin Sides

\begin{tabular}{|c|c|c|c|c|c|c|c|}
\hline \multirow{2}{*}{$\begin{array}{l}\text { Days from } \\
\text { operation }\end{array}$} & \multirow{2}{*}{$\mathbf{n}$} & \multicolumn{2}{|c|}{ Carragelose ${ }^{\ominus}$ Side } & \multicolumn{2}{|c|}{ Mupirocin Side } & \multicolumn{2}{|c|}{ Mann-Whitney U-test } \\
\hline & & Median & IQR & Median & IQR & U-score & P-value \\
\hline 4 & 15 & 5.00 & 0.25 & 5.00 & 1.50 & 82.0 & $.217^{\mathrm{ns}}$ \\
\hline 7 & 14 & 4.00 & 2.25 & 5.00 & 2.25 & 70.5 & $.210^{\mathrm{ns}}$ \\
\hline 14 & 10 & 3.00 & 1.50 & 4.00 & 2.00 & 40.0 & $.481^{\mathrm{ns}}$ \\
\hline 28 & 10 & 2.00 & 1.25 & 3.00 & 3.25 & 33.0 & $.218^{\text {ns }}$ \\
\hline \multirow{4}{*}{\multicolumn{2}{|c|}{ Friedman Test }} & \multicolumn{2}{|c|}{$\mathrm{n}=10$} & \multicolumn{2}{|c|}{$n=10$} & & \\
\hline & & \multicolumn{2}{|c|}{$\mathrm{df}=3$} & \multicolumn{2}{|c|}{$d f=3$} & & \\
\hline & & \multicolumn{2}{|c|}{ Chi-square $=22.3$} & \multicolumn{2}{|c|}{ Chi-square $=15.1$} & & \\
\hline & & \multicolumn{2}{|c|}{ P-value $<.00$ sig } & \multicolumn{2}{|c|}{ P-value $=.002^{\text {sig }}$} & & \\
\hline
\end{tabular}

The overall post-operative outcomes based on Lund-Kennedy Endoscopic Scoring System median scores were significant on day seven (carragelose ${ }^{\circ} \mathrm{Mdn}=2.50, \mathrm{IQR}=2.00$; mupirocin $\mathrm{Mdn}=4.00, \mathrm{IQR}$ $=2.00$ ) [Mann-Whitney $u=50.0 ; p=.027]$. They were not significant on day four (carragelose ${ }^{\circ} \mathrm{Mdn}=3.00, \mathrm{IQR}=2.00$; mupirocin $\mathrm{Mdn}=5.00$, $\mathrm{IQR}=1.00$ ) [Mann-Whitney $u=82.0 ; p=.217$ ]; day 14 (carragelose ${ }^{\circ} \mathrm{Mdn}$ $=2.00, \mathrm{IQR}=4.00$; mupirocin $\mathrm{Mdn}=4.00, \mathrm{IQR}=1.00$ ) [Mann-Whitney $u=39.0 ; p=.171$ ] and day 28 (carragelose $\mathrm{Mdn}=2.00, \mathrm{IQR}=2.00$; mupirocin $M d n=2.00, I Q R=1.00)$ [Mann-Whitney $u=38.5 ; p=.151]$.
The overall post-operative outcomes based on POSE median scores were not significant on day four (carragelose $\mathrm{Mdn}=5.00, \mathrm{IQR}=1.00$; mupirocin $\mathrm{Mdn}=5.00, \mathrm{IQR}=1.00$ ) [Mann-Whitney $u=82.0 ; \mathrm{p}=.217]$; day seven (carragelose ${ }^{\circ} \mathrm{Mdn}=4.00, \mathrm{IQR}=1.00$; mupirocin $\mathrm{Mdn}=5.00$, $\mathrm{IQR}=1.00$ ) [Mann-Whitney $u=70.5 ; \mathrm{p}=.210$ ]; day 14 (carragelose ${ }^{\circ} \mathrm{Mdn}$ $=3.00, \mathrm{IQR}=1.00$; mupirocin Mdn $=4.00, \mathrm{IQR}=1.00$ ) [Mann-Whitney $u=40.0 ; \mathrm{p}=.418$ ] and day 28 (carragelose $\mathrm{Mdn}=2.00, \mathrm{IQR}=3.00$; mupirocin $\mathrm{Mdn}=3.00, \mathrm{IQR}=1.00$ ) [Mann-Whitney $u=33.0 ; \mathrm{p}=.218]$. (Table 4)

\section{DISCUSSION}

Our findings suggest that carragelose nasal spray-impregnated nasal packs may be comparable with mupirocin ointment-impregnated nasal packs in terms of postoperative mucosal healing after ESS for chronic rhinosinusitis with nasal polyposis (CRSwNP).

A previous study by Promentilla et al., found that dexamethasoneimpregnated absorbable nasal packs yielded better post-operative outcomes than saline-impregnated absorbable packing ${ }^{9}$ while a study by Grzeskowiak et al. found that bethamethasone and ciprofloxacinimpregnated nasal packs resulted in a better post-operative healing process than saline. ${ }^{12}$ Another study by Sabarinath et al. found that triamcinolone - impregnated nasal packs decreased mucosal edema and crusting in the post-operative nasal cavity. ${ }^{13}$ The outcomes in the aforementioned studies may be attributed to the anti-inflammatory effect of steroids, but there may be concerns with their safety, adverse effects, and acceptability to prospective users. ${ }^{14}$

(Table 3)

Table 3. Comparison of post-operative outcomes for Carragelose ${ }^{\circledR}$ and Mupirocin Sides based on Lund-Kennedy Endoscopic Scoring System

\begin{tabular}{|c|c|c|c|c|c|c|c|c|c|c|c|c|c|c|c|c|}
\hline \multirow{3}{*}{ Lund-Kennedy } & \multicolumn{4}{|c|}{ Day 4} & \multicolumn{4}{|c|}{ Day 7} & \multicolumn{4}{|c|}{ Day 14} & \multicolumn{4}{|c|}{ Day 28} \\
\hline & \multicolumn{2}{|c|}{ Carragelose $^{\oplus}$} & \multicolumn{2}{|c|}{ Mupirocin } & \multicolumn{2}{|c|}{ Carragelose $^{\oplus}$} & \multicolumn{2}{|c|}{ Mupirocin } & \multicolumn{2}{|c|}{ Carragelose $^{\oplus}$} & \multicolumn{2}{|c|}{ Mupirocin } & \multicolumn{2}{|c|}{ Carragelose $^{\circledR}$} & \multicolumn{2}{|c|}{ Mupirocin } \\
\hline & Md & IQR & Md & IQR & Md & IQR & Md & IQR & Md & IQR & Md & IQR & Md & IQR & Md & IQR \\
\hline Polyp & 0.00 & 0.00 & 0.00 & 0.00 & 0.00 & 0.00 & 0.00 & 1.00 & 0.00 & 0.00 & 0.00 & 0.00 & 0.00 & 0.00 & 0.00 & 0.00 \\
\hline U-score $\mid P$-value & \multicolumn{2}{|c|}{97.50} & \multicolumn{2}{|c|}{.539} & \multicolumn{2}{|c|}{76.5} & \multicolumn{2}{|c|}{.329} & \multicolumn{2}{|c|}{55.0} & \multicolumn{2}{|c|}{.748} & \multicolumn{2}{|c|}{60.5} & \multicolumn{2}{|c|}{1.000} \\
\hline Edema & 2.00 & 1.00 & 2.00 & 1.00 & 1.00 & 1.00 & 1.00 & 1.00 & 1.00 & 1.00 & 1.00 & 1.00 & 0.00 & 1.00 & 1.00 & 1.00 \\
\hline$U$-score $\mid P$-value & \multicolumn{2}{|c|}{105.5} & \multicolumn{2}{|c|}{.775} & \multicolumn{2}{|c|}{98.0} & \multicolumn{2}{|c|}{1.00} & \multicolumn{2}{|c|}{51.5} & \multicolumn{2}{|c|}{.562} & \multicolumn{2}{|c|}{39.0} & \multicolumn{2}{|c|}{.171} \\
\hline Discharge & 1.00 & 1.00 & 1.00 & 1.00 & 0.00 & 1.00 & 1.00 & 1.00 & 1.00 & 1.00 & 1.00 & 1.00 & 1.00 & 1.00 & 1.00 & 0.00 \\
\hline U-score $\mid P$-value & \multicolumn{2}{|c|}{109.5} & \multicolumn{2}{|c|}{.902} & \multicolumn{2}{|c|}{38.5} & \multicolumn{2}{|c|}{.050} & & & & & & & & \\
\hline Scarring & 0.00 & 1.00 & 0.00 & 1.00 & 0.00 & 1.00 & 1.00 & 1.00 & 0.00 & 1.00 & 1.00 & 1.00 & 0.00 & 0.00 & 0.00 & 1.00 \\
\hline U-score $\mid P$-value & & & & & & & & & & & & & & & & \\
\hline Crusting & 0.00 & 2.00 & 1.00 & 2.00 & 1.00 & 1.00 & 1.00 & 0.00 & 0.00 & 1.00 & 1.00 & 1.00 & 0.00 & 0.00 & 0.00 & 0.00 \\
\hline U-score $\mid P$-value & & & & & & & & & & & & & & & & \\
\hline Overall LUND & 3.00 & 2.00 & 5.00 & 1.00 & 2.50 & 2.00 & 4.00 & 2.00 & 2.00 & 4.00 & 4.00 & 1.00 & 2.00 & 2.00 & 2.00 & 1.00 \\
\hline U-score $\mid P$-value & & & & & & & & & & & & & & & & \\
\hline
\end{tabular}

significant using Mann-Whitney U-test 
ORIGINAL ARTICLES

Table 4. Comparison of post-operative outcomes for Carragelose ${ }^{\circledast}$ and Mupirocin Sides based on POSE

\begin{tabular}{|c|c|c|c|c|c|c|c|c|c|c|c|c|c|c|c|c|}
\hline \multirow{3}{*}{ POSE } & \multicolumn{4}{|c|}{ Day 4} & \multicolumn{4}{|c|}{ Day 7} & \multicolumn{4}{|c|}{ Day 14} & \multicolumn{4}{|c|}{ Day 28} \\
\hline & \multicolumn{2}{|c|}{ Carragelose $^{\oplus}$} & \multicolumn{2}{|c|}{ Mupirocin } & \multicolumn{2}{|c|}{ Carragelose $^{\circledR}$} & \multicolumn{2}{|c|}{ Mupirocin } & \multicolumn{2}{|c|}{ Carragelose $^{\circledR}$} & \multicolumn{2}{|c|}{ Mupirocin } & \multicolumn{2}{|c|}{ Carragelose $^{\circledR}$} & \multicolumn{2}{|c|}{ Mupirocin } \\
\hline & Md & IQR & Md & IQR & Md & IQR & Md & IQR & Md & IQR & Md & IQR & Md & IQR & Md & IQR \\
\hline Middle Turbinate & 1.00 & 0.00 & 1.00 & 0.00 & 1.00 & 1.00 & 1.00 & 1.00 & 0.00 & 0.00 & 0.00 & 0.00 & 0.00 & 0.00 & 0.00 & 0.00 \\
\hline $\mid$ U-score $\mid P$-value & \multicolumn{2}{|c|}{87.0} & \multicolumn{2}{|c|}{.305} & \multicolumn{2}{|c|}{44.0} & \multicolumn{2}{|c|}{.190} & \multicolumn{2}{|c|}{50.0} & \multicolumn{2}{|c|}{1.00} & \multicolumn{2}{|c|}{50.0} & \multicolumn{2}{|c|}{1.00} \\
\hline $\begin{array}{l}\text { Middle Meatus: } \\
\text { Stenosis }\end{array}$ & 1.00 & 1.00 & 1.00 & 1.00 & 1.00 & 1.00 & 1.00 & 1.00 & 0.00 & 0.00 & 0.00 & 0.00 & 0.00 & 0.00 & 0.00 & 1.00 \\
\hline U-score $\mid P$-value & \multicolumn{2}{|c|}{108.5} & \multicolumn{2}{|c|}{.870} & \multicolumn{2}{|c|}{58.0} & \multicolumn{2}{|c|}{.561} & \multicolumn{2}{|c|}{45.0} & \multicolumn{2}{|c|}{.739} & \multicolumn{2}{|c|}{41.5} & \multicolumn{2}{|c|}{.529} \\
\hline $\begin{array}{l}\text { Middle Meatus: } \\
\text { Maxillary Sinus } \\
\text { Content }\end{array}$ & 1.00 & 0.00 & 1.00 & 0.00 & 1.00 & 0.00 & 1.00 & 0.00 & 0.00 & 0.00 & 0.00 & 1.00 & 0.00 & 0.00 & 0.00 & 1.00 \\
\hline U-score $\mid$ P-value & \multicolumn{2}{|c|}{$\frac{1}{112.5}$} & & & & & & & & & & & & & & \\
\hline Mucosal Edema & 1.00 & 1.00 & 1.00 & 0.00 & 1.00 & 0.00 & 1.00 & 0.00 & 1.00 & 1.00 & 1.00 & 1.00 & 0.50 & 1.00 & 1.00 & 1.00 \\
\hline U-score $\mid$ P-value & & & & & & & & & & & & & & & & \\
\hline \begin{tabular}{|l} 
Polypoid Change \\
\end{tabular} & 0.00 & 0.00 & 0.00 & 0.00 & 0.00 & 0.00 & 0.00 & 0.00 & 0.00 & 1.00 & 0.00 & 1.00 & 0.00 & 0.00 & 0.00 & 0.00 \\
\hline \begin{tabular}{|l|l|} 
U-score & $P$-value \\
\end{tabular} & & & & & & & & & & & & & & & & \\
\hline Polyposis & 0.00 & 0.00 & 0.00 & 0.00 & 0.00 & 0.00 & 0.00 & 0.00 & 0.00 & 1.00 & 0.00 & 1.00 & 0.00 & 1.00 & 0.00 & 0.00 \\
\hline U-score $\mid P$-value & & & & & & & & & & & & & & & & \\
\hline \begin{tabular}{|l} 
Discharge \\
\end{tabular} & 0.00 & 1.00 & 0.00 & 1.00 & 0.00 & 1.00 & 1.00 & 0.00 & 1.00 & 1.00 & 1.00 & 1.00 & 0.00 & 1.00 & 0.50 & 1.00 \\
\hline U-score $\mid P$-value & & & & & & & & & & & & & & & & \\
\hline Crusting & 0.00 & 1.00 & 1.00 & 1.00 & 0.00 & 1.00 & 0.00 & 0.50 & 0.50 & 1.00 & 0.50 & 1.00 & 0.00 & 0.00 & 0.00 & 0.00 \\
\hline U-score |P-value & & & & & & & & & & & & & & & & \\
\hline Overall POSE & 5.00 & 1.00 & 5.00 & 1.00 & 4.00 & 1.00 & 5.00 & 1.00 & 3.00 & 1.00 & 4.00 & 1.00 & 2.00 & 3.00 & 3.00 & 1.00 \\
\hline U-score $\mid P$-value & & & & & & & & & & & & & & & & \\
\hline
\end{tabular}

${ }^{\mathrm{s}}$ significant using Mann-Whitney U-test

Carragelose (or carrageenan) appears to be a potent inflammatory agent, demonstrated in an experiment on rodent and mice leucocytes to produce tumor necrosis factor - alpha and a potent macrophage activator. ${ }^{15}$ Perhaps the anti-inflammatory effect is mediated by the action of macrophages on neutrophilic inflammation that occurs during wound repair. ${ }^{16}$

In contrast with steroids, carragelose ${ }^{\circ}$ when used as a topical medication intranasally is relatively safe. Hebar et al. claim that $0.12 \%$ iota-carrageenan (active ingredient of carragelose nasal spray) applied intranasally will not penetrate nasal mucosa and does not reach the blood stream, concluding that it is clinically safe specially when applied topically on nasal mucosa. ${ }^{17}$ Given its mechanism to promote wound healing and its other biological attributes, carragelose may be a promising post-operative medication on patients who underwent ESS.

Because our study can only suggest that carragelose and mupirocin may be comparable in terms of a relatively good effect on postoperative mucosal healing, a trial involving a larger sample should be initiated to validate these findings.
The Lund and Kennedy Endoscopic Scoring System ${ }^{10}$ and Wright and Agrawal's Perioperative Sinus Endoscopy Scoring System or the POSE Scoring System ${ }^{11}$ were used in this study. Using the 2-scoring systems may confer advantages in terms of content validity and sensitivity to change with the additional information regarding secondary sinuses and the ethmoid cavity.$^{16}$ Although reliable, using POSE was taxing on the part of the blinded consultant because of the detailed features of the parameters especially when grading in 4 separate sessions.

Limitations of this study include lack of randomization that should have been initiated at the outset to minimize differences and to ensure equal chances of distribution, in this case both nasal cavities. The small sample size of participants that completed the study is another limitation. Instead of the minimum computed sample size of 16 per group ( 32 sides), we ended up with only 6 participants ( 12 sides). Ideally, both drugs should have been concealed in similar containers although this was not feasible because of the differing consistencies 
(liquid in a plastic bottle and ointment in tube form) of the commercially available stock preparations in the market. However, we believe that both patients and the consultant who evaluated the videorecorded endoscopic examinations were sufficiently blinded.

For future studies, we recommend increasing the number of participants to meet the minimum sample size, ensuring proper randomization, using similar containers, using a simple but reliable scoring system, and limiting the number of days of observation.

Despite all these limitations, the findings of our study may still suggest that carrageenan nasal spray impregnated nasal packs are comparable with mupirocin ointment coated nasal packs and may be a viable alternative for post-operative care among patients who undergo ESS.

\section{REFERENCES}

1. Vermin A, Seneldir L, Naiboglu B, Karace CT, Kulekci S, Toros SZ, Oysu C. Role of nasal packing in surgical outcome for chronic rhinosinusitis with polyposis. Laryngoscope. 2014 Jul; 124(7):152935. DOI: 10.1002/lary.24543. PubMed PMID: 24284971.

2. Michael P, Farid M, Kwok M, O'Leary S. Routine nasal packing versus no nasal packing following functional endoscopic sinus surgery. Cochrane Database of Systematic Reviews. 2016 Sep 27 2016 (9). DOI: 10.1002/14651858.CD011587.pub2. PubMed Central PMCID: PMC6457635.

3. Chang EH, Alandejani T, Akbari E, Ostry A, Javer A. Double-blinded, randomized, controlled trial of medicated versus nonmedicated merocel sponges for functional endoscopic sinus surgery. J Otolaryngol Head Neck Surg. 2011 Feb. 40:S14-S19. PubMed PMID: 21453656.

4. Suat B, Yusuf MD, Ozgur Y, Aysel K, Cansu C, Muzaffer F, Ali Riza G. The effect of mupirocinand fusidic acid-nasal packings, placed after septoplasty, on the nasal bacterial profile. Allergy Rhinol. 2016; 7(4):e207-e212. DOI: 10.2500/ar.2016.7.0181. PubMed PMID: 28683247 PubMed Central PMCID: PMC5244280.

5. Xu JJ, Bustato GM, C. McKnight, J.M. Lee. Absorbable steroid-impregnated spacer after endoscopic sinus surgery to reduce synechiae formation. Ann Otol Rhinol Laryngol. 2016. 125:195-198. . DOI: 10.1177/0003489415606446. PubMed PMID: 26391092.

6. Necas J, Bartosikova L. Carrageenan: a review. Veterinarni Medicina. 2013; 58(4): 187-205. Available from: http://vri.cz/docs/vetmed/58-4-187.pdf.

7. Koenighofer $M$, Lion $T$, Bodenteich $A$, Prieschl-Grassauer $E$, Grassauer $A$, Unger $H$, et al. Carrageenan nasal spray in virus confirmed common cold: individual patient data analysis of two randomized controlled trials. Multidiscip Respir Med. 2014 Nov; 9(1):57. DOI: 10.1186/20496958-9-57.

8. Eccles R, Winther B, Johnston SL, Robinson P, Trampisch M, Koelsch S. Efficacy and safety of iotacarrageenan nasal spray versus placebo in early treatment of the common cold in adults: the ICICC trial. Respir Res. 2015 Oct;16:121. DOI: 10.1186/s12931-015-0281-8.

9. Promentilla SMA, Onofre RDC, Campomanes BSA. Effects of dexamethasone versus saline-impregnated nasal packing on the postoperative outcome of patients with chronic rhinosinusitis and nasal polyps after endoscopic sinus surgery: a randomized controlled trial. Philipp J Otolaryngol Head Neck Surg. 2016 Jan-Jun; 31(1):10-13. DOI: https://doi.org/10.32412/ pjohns.v31i1.301.

10. De Conde A, Bodner T, Mace J, Alt J, Rudmik L, Smith T. Development of a Clinically Relevant Endoscopic Grading System for Chronic Rhinosinusitis using Canonical Correlation Analysis. In Forum Allergy Rhinol. 2016 May; 6(5): 478-485. DOI:10.1002.

11. Côté D, Wright E. Objective Outcomes in Endoscopic Sinus Surgery. Advances in Endoscopic Surgery. 2011 November 25. Available from: http://www.intechopen.com/books/advances-inendoscopic-surgery/objective-outcomes-in-endoscopic-sinus- surgery. DOI: 10.5772/22191.

12. Grzeskowiak B, Wierzchowska M, Walorek R, Seredyka-Burduk M, Wawrzyniak K, Burduk PK. Steroid vs. antibiotic impregnated absorbable nasal packing for wound healing after endoscopic sinus surgery: a randomized, double blind, placebo-controlled study. Braz Otorhinolaryngol. Jul-Aug 2019; 85(4):473-480. DOI: 0.1016/j.bjorl.2018.04.002. PubMed PMID: 29807811.

13. Sabarinath V, Harish MR, Divakaran S. Triamcinolone Impregnated Nasal Pack in Endoscopic Sinus Surgery: Our Experience. Indian J Otolaryngol Head Neck Surg. 2017 Mar; 69(1):88-92. DOI 10.1007/s12070-016-1041-x. PubMed PMID: 28239586 PubMed Central PMCID: PMC5305642.

14. Kimmerle R, Rolla AR. latrogenic Cushing's syndrome due to dexamethasone nasal drops. Am J Med. 1985 Oct; 79(4):535-7. DOI: 10.1016/0002-9343(85)90046-4. PubMed PMID: 4050838.

15. Wright ED, Agrawal S. Impact of perioperative systemic steroids on surgical outcomes in patients with chronic rhinosinusitis with polyposis: evaluation with the novel perioperative sinus endoscopy (POSE) scoring system. Laryngoscope. 2007 Nov; 117(115):1-28. DOI: 10.1097/ MLG.0b013e31814842f8. PubMed PMID: 18075447.

16. Pajić-Penavić I. Endoscopic Monitoring of Postoperative Sinonasal Mucosa Wounds Healing Advances in Endoscopic Surgery. 2011; 419-436. DOI: 10.5772/21868

17. Hebar A, Koller C, Seifert J-M, Chabicovsky M, Bodenteich A, Bernkop-Schnürch A, et al. Nonclinical safety evaluation of intranasal iota-carrageenan. PLoS One. 2015 Apr; 10(4):e0122911. DOI: 10.1371/journal.pone.0122911. PubMed PMID: 25875737 PubMed Central PMCID: PMC4395440. 